\title{
The effect of transplantation of adipose-derived stem cells to spinal cord on the recovery of urinary bladder function in patients having spinal cord injuries: a urodynamic study Ahmad El Zayat ${ }^{\mathrm{a}}$, Yasser Badran ${ }^{\mathrm{b}}$
}

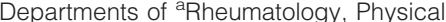 \\ Medicine and Rehabilitation, burology, Al Azhar \\ University, Cairo, Egypt \\ Correspondence to Ahmad El-Zyat, MD, \\ Rheumatology, Physical Medicine and \\ Rehabilitation Department, Al Azhar University, \\ Cairo, Egypt. \\ e-mail: arz12003@hotmail.com \\ Received 4 February 2018 \\ Accepted 19 April 2018
}

Egyptian Rheumatology \& Rehabilitation 2018, 45:100-105

\begin{abstract}
Introduction
Stem cells transplantation, as a therapeutic intervention for spinal cord injury (SCI), has been extensively studied by researchers in recent years.

Our study aimed to study the effect of transplantation of adipose-derived stem cells into spinal cord by intrathecal injection on the recovery of urinary bladder function assessed by a urodynamics study in patients having SCls.

Patients and methods

A total of 69 patients who had cervical incomplete tetraplegia were divided into two groups: group 1 had 37 patients who were treated with adipose-derived stem cells transplanted into spinal cord via intrathecal injection and were assessed by a urodynamic study before stem cell transplantation and then 6 months and 1 year after transplantation, and group 2 had 32 patients who underwent rehabilitation program only and were assessed by a urodynamic study before starting rehabilitation and then 6 months and 1 year after program.

Results

Eight $(21.62 \%)$ patients benefitted from stem cells transplantation into spinal cord regarding urinary bladder function as assessed by urodynamics in varying degrees, but there was no significant difference between both groups.

Conclusion

Stem cells transplantation is a promising treatment for patients having $\mathrm{SCl}$.
\end{abstract}

\section{Keywords:}

spinal cord injury, stem cell transplantation, urodynamics

Egypt Rheumatol Rehabil 45:100-105

(C) 2018 Egyptian Society for Rheumatology and Rehabilitation

1110-161X

\section{Introduction}

The main cause of spinal cord injury (SCI) is direct mechanical damage, which results in complete or incomplete loss of neural functions either motor or sensory; the most frequent causes of SCI are motor vehicle accidents, falls, and acts of violence [1].

The pathophysiological processes of SCI have two phases: the primary phase is the mechanical effect of trauma to the spinal cord, causes spinal cord tissue to be disrupted by the force of the primary injury [2].

The secondary is the posttraumatic inflammatory response, and it plays an important role through a complex series of modulation of cellular and molecular interactions, which include neuronal cell death, loss of oligodendrocytes, inflammation, and reactive astrogliosis [3].

SCI, one of the most common causes of neurogenic detrusor dysfunction in young adults, may be associated with neurogenic detrusor overactivity. The patients with neurogenic detrusor dysfunction should be treated to preserve renal function, promote urinary continence, avoid urinary tract infection, and preserve quality of life [4].

Urinary continence is the absence of urinary leakage in the intervals between intermittent catheterization [5].

Stem cell transplantation to spinal cord, as a therapeutic intervention for management of SCI, has been studied in recent years. There are many kinds of stem cells, including adult stem cells, embryonic stem cells and induced pluripotent stem cells, used in cases of SCI [6].

Stem cells are characterized by their ability to differentiate into various cell types and self-renewing ability. Stem cells secrete substances like growth factor, cytokine, and trophic factor, which help neuroprotection [7].
This is an open access journal, and articles are distributed under the terms of the Creative Commons Attribution-NonCommercial-ShareAlike 4.0 License, which allows others to remix, tweak, and build upon the work non-commercially, as long as appropriate credit is given and the new creations are licensed under the identical terms. 
There are many types of stem cells: embryonic stem cells are pluripotent stem cells owing to its ability to be differentiate to three germs layer, and adult stem cells are multipotent stem cells that have limited ability to differentiation [8].

Stem cell therapy plays a role in the treatment of SCI by replacement of neuronal cells, preservation of glial cells, remyelination of axons, increased trophic molecules, angiogenesis, bridging of cavities, reduction of inflammation, and stimulation of endogenous precursor cells for neuronal plasticity [9].

\section{Patients and methods}

This study was carried out in Abdul Latif Jameel Hospital in KSA from May 2010 until December 2016.

A total of 69 patients with SCI and Neurogenic Detrusor Overactivity were included in this study. The study included 47 male and 22 female patients, with their age ranging from 18 to 31 years old, who had cervical SCI from $\mathrm{C} 5$ to $\mathrm{C} 7$ of more than 6 months and less than 1 year of incomplete tetraplegia and who had been regularly undergoing clean intermittent catheterization. As patients had incomplete tetraplegia, intermittent catheterization was done by a nurse every 4,6 or $8 \mathrm{~h}$ according to the residual volume of patients. Exclusion criteria were patients with chronic diseases, patients using any antimuscarinic medication, patients receiving Botox injection at detrusor muscle, and patients having received previous stem cell therapy.

All 69 patients were clinically evaluated for neurologic complications according to the American Spinal Injury Association recommendation [10]. Laboratory evaluation included measurement of serum urea and creatinine, urinalysis, urine culture with antimicrobial susceptibility testing, and abdominal ultrasound. Any patients having associated brain injury, congenital anomalies, or incontinent of urine were excluded.

The urodynamic study was done by a urologist according to the recommendations of the International Continence Society [11]. Urodynamic parameters were detecting according to the International Continence Society standardization [12].

The urodynamic study detects bladder sensation, bladder capacity, detrusor pressure, presence of detrusor overactivity and volume of urine at which autonomic dysreflexia occurs by monitoring blood pressure and demonstrate clinical picture of patients like sweating, headache, bradycardia, anxiety and blurring of vision during test.

The urodynamics study was done before the start of treatment and then 6 and 12 months after treatment.

Written consents were taken from all patients before examination and before any procedure for their inclusion in this study.

\section{Division of patients into two groups}

Group 1 had 37 patients who were treated with stem cells transplantation at a private clinic, where stem cells were prepared from fat cells of patients themselves and were injected into the spinal canal.

Patients were discharged one day before transplantation and readmitted $2^{\text {nd }}$ day after transplantation, and after undergoing stem cells transplantations, patients just went out of pass and came second day after transplantation.

In this study, we used adipose-derived stem cells isolated from abdominal subcutaneous adipose tissue by clinical pathologist [13].

Subcutaneous adipose tissue was taken from patients by an orthopedic surgeon, and stem cells were injected by the orthopedic surgeon in the spinal canal of patients.

All 37 patients are reevaluated by previous assessment and investigation after treatment by stem cells transplantation.

Group 2 included 32 patients who received only rehabilitation program, and intermittent catheterization by nylon catheter was done a by nurse every 4,6 or $8 \mathrm{~h}$ according to the volume of urine of patients. The rehabilitation program extended for 1 year. Thirteen of patients stay in hospital remaining patients stay in hospital 6 months then discharge to home with regular follow-up.

\section{Results}

Group 1 had 37 patients, with 12 (32.43\%) female and $25(68.57 \%)$ male. All have cervical 5-6 incomplete tetraplegia ASIA C.

Their ages varied between 19 and 24 years, with a mean of $21.57 \pm 1.72$ years.

Urodynamic study was done for all patients before stem cells transplantation, and then 6 months and 1 year after stem cells transplantation. 
In our study, only eight patients showed improvement in group 1, so we present the results of these eight patients separately and then we present the results of all groups together.

There was improvement in suprapubic sensation in the first 6 months after transplantation in four (10.81\%) patients and after 1 year in six (16.22\%) patients.

There were two (5.40\%) patients who passed urine by the end of 1 year after transplantation.

The capacity of bladder was improved in seven (18.92\%) patients.

There was significant improvement in bladder capacity in seven (18.92\%) patients after 6 months from 87.86 \pm 26.44 to $131.57 \pm 52.44 \mathrm{ml}$, which became highly significant after 1 year to be $193.26 \pm 79.38 \mathrm{ml}$.

Regarding detrusor over activity, it completely subsided in three (8.11\%) patients after 1 year from stem cells transplantation.

The detrusor pressure was reduced in five (13.51\%) patients from $82.57 \pm 12.83$ to $68.43 \pm 13.11 \mathrm{~cm} / \mathrm{H}_{2} \mathrm{O}$ after 6 months from stem cells transplantation, which is nonsignificant, but after 1 year, it significantly reduced to $46.86 \pm 78.44 \mathrm{~cm} / \mathrm{H}_{2} \mathrm{O}$.
Occurrence of autonomic dysreflexia (AD) was improved in eight $(21.62 \%)$ patients regarding amount of urine, at which the occurrence and manifestation of $\mathrm{AD}$ became less severe.

The improvement in eight (21.62\%) patients in occurrence of manifestation of $\mathrm{AD}$; it was occurred when volume of urine were $77.00 \pm$ $23.37 \mathrm{ml}$ before stem cell transplantation which occurred at $116.14 \pm 45.24 \mathrm{ml} 6$ month after transplantation which is significant improvement and after 1 year AD start to appear at $183.45 \pm 78.44$ which is highly significant improvement.

AD manifestations completely disappeared in three (8.11\%) patients and improved in five (13.51\%) patients. Before transplantation, they presented as hypertension, sweating and headache; after 6 months of transplantation, became headache and sweating; and 1 year after transplantation became only sweating.

The results of eight patients who showed improvement are shown in Table 1 and Fig. 1.

Among all patients in group 1, there was a nonsignificant improvement in all measurements of urodynamics, as shown in Table 2 .

Table 1 Shows results of improvement in eight patients

\begin{tabular}{lccccc}
\hline & Before transplantation & After 6 months & $P$-value & After 1 year & $P$-value \\
\hline Capacity $(\mathrm{ml})$ & $87.86 \pm 26.44$ & $131.57 \pm 52.44$ & $<0.05^{\star}$ & $193.29 \pm 79.38$ & $<0.01^{\star *}$ \\
DOA $\left(\mathrm{cm} / \mathrm{H}_{2} \mathrm{O}\right)$ & $82.57 \pm 12.83$ & $68.43 \pm 13.11$ & 0.1 & $46.86 \pm 34.64$ & $<0.05^{*}$ \\
AD $(\mathrm{ml})$ & $77.00 \pm 23.37$ & $116.14 \pm 45.24$ & $<0.05^{\star}$ & $183.43 \pm 78.44$ & $<0.01^{* *}$ \\
\hline
\end{tabular}

$\mathrm{AD}$, autonomic dysreflexia; $\mathrm{DOA}$, detrusor overactivity.

\section{Figure 1}

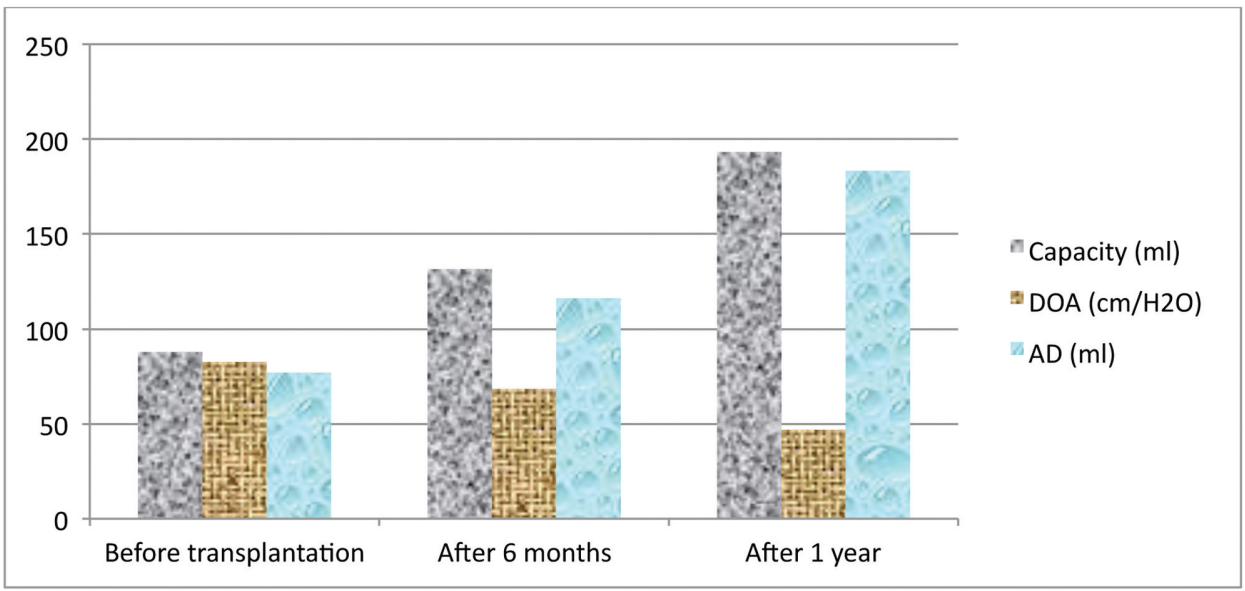

Shows improvement in urodynamic before and after stem cells transplantations in eight patients.AD, autonomic dysreflexia; DOA, detrusor overactivity. 
Group 2 had 32 patients, with 10 (31.25\%) females and $22(68.75 \%)$ males, and all had cervical 5-6 incomplete tetraplegia ASIA C.

There ages varied between 19 and 24 years, with mean of $21.37 \pm 2.03$ years.

Urodynamic study was done for all patients before the start of rehabilitation, and then 6 months and 1 year after the start of rehabilitation.

Among all patients in group 2, there was a nonsignificant improvement in all measurements of urodynamics, as shown in Table 3.

\section{Discussion}

To our knowledge, this is the first study to utilize urodynamic to assess patients having SCI who underwent adipose-derived stem cells transplantation to spinal cord; the previous studies either transplant umbilical cord derivative stem cells or bone marrow derivative stem cells.

An experimental study by Kolar et al. [14] in rats having SCI stated that transplantation of adiposederived stem cells to spinal cord can modify the structure of the glial scar and stimulate axonal sprouting.

In our study, we found that only eight (21.62\%) patients attained benefits from stem cells transplantation, but to varying degrees; the improvement was significant in those patients only, but there was a nonsignificant improvement among group 1 . Therefore, we present the results of these eight patients separately.

In our study we found that (5.40\%) 2 patients already void urine normally 1 year after transplantation which before transplantation was had autonomic bladder which consider as excellent response.

Although three (8.10\%) patients showed improvement in the disappearance of detrusor overactivity, improvement in bladder capacity occurred in seven (18.92\%) patients.

The detrusor pressure was significantly reduced in five (13.51\%) patients.

Occurrence of autonomic dysreflexia (AD) was significantly improved in $8(21.62 \%)$ patients regarding amount of urine at which it occur and manifestation of $\mathrm{AD}$ became less.

AD manifestations completely disappeared in three (8.11\%) patients and improved in five (13.51\%) patients; before transplantation, they presented as hypertension, sweating and headache; 6 month after transplantation became headache and sweating; and 1 year after transplantation became only sweating.

In the remaining $30(81.08 \%)$ patients, there is improvement in manifestation of $\mathrm{AD}$, which is significant in the patients.

On comparison between the two groups, there was no significant difference in improvement in urodynamics, but some patients got benefits, which is considered a good hope for patients; so we recommend further studies that include a high number of patients.

Our study agreed with Kim et al. [15] who found that the use of stem cell therapy in SCI produces partial bladder recovery, including improvement of voiding pressure, nonvoiding contraction, and amount of residual urine, and they stated that the use of neuroregeneration in stem cell therapy to correct bladder dysfunction is a logical and promising strategy. However, their study used bone marrow-

Table 2 Shows result of group 1

\begin{tabular}{lccccc}
\hline & Before transplantation & After 6 months & $P$-value & After 1 year & $P$-value \\
\hline Capacity $(\mathrm{ml})$ & $89.96 \pm 27.32$ & $94.78 \pm 32.25$ & $>0.05$ & $96.47 \pm 39.45$ & $>0.05$ \\
DOA $\left(\mathrm{cm} / \mathrm{H}_{2} \mathrm{O}\right)$ & $81.61 \pm 11.94$ & $78.32 \pm 14.22$ & $>0.05$ & $68.57 \pm 19.36$ & $>0.05$ \\
AD $(\mathrm{ml})$ & $78.24 \pm 23.56$ & $83.35 \pm 28.61$ & $>0.05$ & $85.58 \pm 32.36$ & $>0.05$ \\
\hline
\end{tabular}

$A D$, autonomic dysreflexia; $D O A$, detrusor over activity.

Table 3 Shows results of urodynamics changes in group 2

\begin{tabular}{lcccc}
\hline & Before transplantation & After 6 months & $P$-value & After 1 year \\
\hline Capacity $(\mathrm{ml})$ & $86.78 \pm 31.56$ & $89.21 \pm 33.22$ & $>0.05$ & $90.89 \pm 41.63$ \\
DOA $\left(\mathrm{cm} / \mathrm{H}_{2} \mathrm{O}\right)$ & $78.89 \pm 13.93$ & $76.45 \pm 15.84$ & $>0.05$ & $75.39 \pm 20.18$ \\
AD $(\mathrm{ml})$ & $83.69 \pm 27.92$ & $85.16 \pm 29.72$ & $>0.05$ & $86.57 \pm 33.04$ \\
\hline
\end{tabular}

$A D$, autonomic dysreflexia; DOA, detrusor over activity. 
derived stem cell transplantation, which is different from our study.

Cheng et al. [16] studied the effect of spinal stem cell transplantation injected intrathecally on the outcome of patients having SCI and found that seven of the 10 patients had significant improvement in movement, self-care ability, and muscular tension; urodynamic examination demonstrated that patients exhibited an increase in maximum urinary flow rate and maximum bladder capacity, as well as a decrease in residue urine volume and maximum detrusor pressure. This agrees with our study in that there were improvements in bladder capacity and decrease in residue urine volume and maximum detrusor pressure, but in their study, they used umbilical stem cell, whereas in our study, we used adipose-derived stromal stem cells.

Shroff and Barthakur [17] found that there were improvement in bowel and bladder control and sensation in patients with SCI after human embryonic stem cell therapy; this study was carried out on 226 patients with SCI where human embryonic stem cell were administered intramuscularly twice daily, every 10 days through intravenous route and every 5-7 days by any of the supplemental routes. It found that bowel sensation became normal in seven (3.5\%) patients, bladder sensation became normal in seven (3.4\%) patients, mild improvement in sensation of bowel fullness in 135 (67.5\%) patients, and mild improvement in sensation of bladder filling in 155 (76\%) patients. Moreover, bowel control became normal in four (2\%) patients, bladder control became normal in four (1.9\%) patients, 95 (46.8\%) patients had bowel control, and 113 (54\%) patients had bladder control. This study was in agreement with our study from the point that there were improvements of bladder sensation and control in some patients, as in our study we found improvement of bladder sensation in patients and control in two patients. However, it was different from our study, as they use human embryonic stem cell but we use stromal stem cell and they inject intramuscular and intravenous, but in our, study injection was intrathecal.Larocca et al. [18] stated that intralesional transplantation of autologous mesenchymal stem cells in patients with chronic, complete SCI is safe and feasible and may promote bladder function improvements. Their study was carried out on 14 patients having SCI, where bone marrow stem cells were injected in the intralesion of the spinal cord and found that nine patients had improvements in bladder function; five had an increase in maximum bladder capacity, where one of these patients presented appearance of bladder sensation which was previously absent; and four patients has decrease detrusor overactivity. This study agreed with ours about improvement of bladder function in some patient with stem cells, but in their study, they used bone marrow-derived stem cells, whereas in our study, we use adipose-derived stromal stem cells.

\section{Conclusion}

Stem cells transplantation is a promising treatment for patients who have SCI. We found that some patients had significant improvement in their urinary bladder function, which is a good hope for patients having SCI.

\section{Recommendation}

The effect of stem cells transplantation on recovery of urinary bladder in patients having SCIs needs more researches to detect the best way to reach significant improvement in all functions of urinary bladder.

\section{Financial support and sponsorship \\ Nil.}

\section{Conflicts of interest}

There are no conflicts of interest.

\section{References}

1 Yip PK, Malaspina A. Spinal cord trauma and the molecular point of no return. Mol Neurodegener 2012; 7:6.

2 Sekhon LHS, Fehlings MG. Epidemiology, demographics, and pathophysiology of acute spinal cord injury. Spine 2001; 26(Suppl 24):S2-S12.

3 Thuret S, Moon LDF, Gage FH. Therapeutic interventions after spinal cord injury. Nat Rev Neurosci 2006; 7:628-643.

4 Pannek J, Kullik B. Does optimizing bladder management equal optimizing quality of life? correlation between health-related quality of life and urodynamic parameters in patients with spinal cord lesions. Urology 2009; 74:263-266.

5 Pannek J, Gocking K, Bersch U. Long-term effects of repeated intradetrusor botulinum neurotoxin $\mathrm{A}$ injections on detrusor function in patients with neurogenic bladder dysfunction. BJU Int 2009; 104: 1246-1250.

6 Grabel L. Prospects for pluripotent stem cell therapies: into the clinic and back to the bench. J Cell Biochem 2012; 113:381-387.

7 Himes BT, Neuhuber B, Coleman C, Kushner R, Swanger SA, Kopen GC. Recovery of function following grafting of human bone marrow-derived stromal cells into the injured spinal cord. Neurorehabil Neural Repair 2006; 20:278-296

8 Vazin T, Freed WJ. Human embryonic stem cells: derivation, culture, and differentiation: a review. Restor Neurol Neurosci 2010; 28:589-603.

9 Mothe AJ, Tator $\mathrm{CH}$. Advances in stem cell therapy for spinal cord injury. J Clin Invest 2012; 122:3824-3834.

10 Maynard FM Jr, Bracken MB, Creasey G, Ditunno JF Jr, Donovan WH, Ducker TB. American spinal injury association. International standards for neurological and functional classification of spinal cord injury. Spinal Cord 1997; 35:266-274.

11 Schafer W, Abrams P, Liao L, Mattiasson A, Pesce F, Spangberg A. Good urodynamic practices: uroflowmetry, filling cystometry, and pressure-flow studies. Neurourol Urodyn 2002; 21:261-274.

12 Abrams P, Cardozo L, Fall M, Griffiths D, Rosier P, Ulmsten U. The standardisation of terminology in lower urinary tract function: report from the standardisation sub-committee of the International Continence Society. Urology 2003; 61:37-49. 
13 Boquest AC, Shahdadfar A, Frønsdal K, Sigurjonsson O, Tunheim SH Collas $\mathrm{P}$, Brinchmann JE. Isolation and molecular profiling of human stromal stem cells derived from adipose tissue. Mol Biol Cell 2005; 24:1294-1301.

14 Kolar MK, Kingham PJ, Novikova LN, Wiberg M, Novikov LN. The therapeutic effects of human adipose-derived stem cells in a rat cervical spinal cord injury model. Stem Cells Dev 2014; 23:1659-1674.

$15 \mathrm{Kim}$ JH, Shim SR, Doo SW, Yang WJ, Yoo BW, Kim JM, et al. Bladder recovery by stem cell based cell therapy in the bladder dysfunction induced by spinal cord. PLoS One 2015; 10:e0113491.
16 Cheng H, Liu X, Hua R, Dai G, Wang X, Gao J, An Y. Clinical observation of umbilical cord mesenchymal stem cell transplantation in treatment for sequelae of thoracolumbar spinal cord injury. J Transl Med 2014; 12:253.

17 Shroff G, Barthakur JK. Bowel/bladder sensation and control in patients with spinal cord injury treated with human embryonic stem cell therapy. EC Neurology 2015; 2:47-54.

18 Larocca T, De Freitas Souza B, Soares M, Mascarenhas F, Santos R. Bladder functional improvements after autologous transplantation of bone marrow mesenchymal stem cells In patients with chronic spinal cord injury: a phase I/II study. Eur Urol 2016; 15:282. 